\title{
Gynecological problems of adolescent girls attending to rural tertiary care centre
}

\author{
Suman Shivanagouda Patil ${ }^{1 *}$, Hemalatha Mahanthshetty ${ }^{1}$, Supriya H. M. ${ }^{1}$, Mahendra M. ${ }^{2}$
}

${ }^{1}$ Department of Obstetrics and Gynecology, ${ }^{2}$ Department of Community Medicine, Sri Devaraj Urs Medical College, Kolar, Karnataka, India

Received: 04 May 2019

Revised: 25 May 2019

Accepted: 01 June 2019

\section{*Correspondence:}

Dr. Suman Shivanagouda Patil,

E-mail: sumidoc4u@gmail.com

Copyright: ( ) the author(s), publisher and licensee Medip Academy. This is an open-access article distributed under the terms of the Creative Commons Attribution Non-Commercial License, which permits unrestricted non-commercial use, distribution, and reproduction in any medium, provided the original work is properly cited.

\section{ABSTRACT}

Background: Adolescence is a transient and dynamic period between childhood and adulthood, characterised by several changes in the body and the child's mind. The World Health Organization defines adolescents as young people aged 10-19 years, but changes may begin before and continue after this age group. Adolescents constitute over $21.4 \%$ of population in India. Adolescence is a period of enormous physical and psychological change for young girls. Hormonal events play a key role in this transition. One of the major physiological changes that take place in adolescent girls is the onset of menarche, which is often associated with problems of irregular menstruation, excessive bleeding and dysmenorrhea. The aim of this study was to determine the proportion of various gynecological problems among adolescent girls seeking care at a tertiary care centre, Kolar, Karnataka, India.

Methods: A cross sectional study was conducted during March 2016 to March 2018 among all adolescent girls (1019 years) with gynecological problems attending inpatient and outpatient Department of Obstetrics and Gynecology. A pre-tested semi-structured questionnaire was used to collect information regarding their socio-demographic characteristics, gynecological history, family history, obstetric history, documentation of general physical examination and other investigations. Data entered using Microsoft Excel and analysed using SPSS v20.

Results: A total of 720 adolescent girls sought care for gynecological problems in the study period with more than $80 \%$ of the cases belonging to the age group between 15 and 19 years. Of the $720,362(49.8 \%)$ had some type of menstrual disorders. Of these 362 cases about 41 of them were a case of puberty menorrhagia (11.32\%) and 89 cases were of dysmenorrhea (22.37\%). Among 720 cases, 290 (40.2\%) of them were diagnosed of teenage pregnancy; among which 34 of them were unwanted pregnancy. Other presentations include vaginal discharge, urinary tract infection, mass per abdomen, trauma to genital tract and turners syndrome (two cases).

Conclusions: The study shows around half of the adolescent girls are having menstrual disorders. One third were teenage pregnancies with most of them been 'wanted'. This alarming finding calls for strengthening of adolescent programme with targeted health education and behavioural change. Setting up a separate adolescent clinics is necessary for efficient management of menstrual disorders in adolescents.

Keywords: Adolescents, Gynecological problems

\section{INTRODUCTION}

Adolescence is a transient and dynamic period between childhood and adulthood, characterised by several changes in the body and the child's mind. ${ }^{1}$
The World Health Organization defines adolescents as young people aged 10-19 years, but changes may begin before and continue after this age group. ${ }^{2}$ There are about 1.2 billion adolescents, one-fifth of the world's population and their number is increasing. Adolescents constitute 
over $21.4 \%$ of population in India. Adolescence is a period of enormous physical and psychological change for young girls. Nutritional deprivation, increased demand of adolescents body, excessive menstrual blood loss all aggravate and exacerbate anemia and its effects. Menstrual disturbances are not uncommon and may add further disruption during this difficult phase for adolescents and their families. ${ }^{3}$

Hormonal events play a key role in this transition. Profund bodily changes, sexual development and altered emotional and behavioral changes are observed during this period, besides endocrine influences, genetic, nutritional and other environmental factors play an important role during this transitional period of life. ${ }^{4}$

Gynecological problems of adolescents occupy a special space in the spectrum of gynecological disorders of all ages. This is because of the physical nature of the problems which are so unique, special, and specific for the age group, and also because of the associated psychological factors which are very important in the growth and psychological remodelling of someone in the transition between childhood and womanhood. ${ }^{5}$

One of the major physiological changes that take place in adolescent girls is the onset of menarche, which is often associated with problems of irregular menstruation, excessive bleeding and dysmenorrhea. ${ }^{6}$

In this study, we have made an attempt to review the gynecological problems encountered in adolescent girls attending the Department of Gynecology at Sri Devaraj Urs Medical College and Hospital and analyzed the menstrual abnormalities in this group.

\section{METHODS}

All adolescent girls with gynecological problems attending to Sri Devaraj Urs Medical College and hospital from March 2016- March 2018 were included in the study. The problems included are the menstrual disorders, unwanted pregnancy, and vaginal discharge, trauma to genital tract, ovarian tumors and evaluation of abdominal mass.

A pre-tested semi-structured questionnaire was used to collect information regarding their socio-demographic characteristics, gynecological history, family history, obstetric history, documentation of general physical examination and other investigations. Investigations like $\mathrm{CBC}$, urine routine, blood sugar, coagulation profile, hormonal assay (FSH, LH, Prolactin, TSH) and pelvic ultrasonography was done when required.

Two years (March 2016-March 2018) cross sectional study conducted at R. L. Jalappa Hospital and Research Center attached to Sri Devaraj Urs Medical College, Kolar, Karnataka, India. Cross sectional study in patients attending to R. L. Jalappa hospital and research centre from March 2016- March 2018.

\section{Inclusion criteria}

- The All adolescent girls with gynecological problems like menstrual disorders, unwanted pregnancy, and vaginal discharge, trauma to genital tract, ovarian tumors, molar pregnancy, infertility, breast tumors, ectopic pregnancy and evaluation of abdominal mass in the age group of 11 to 19 years will be included in the study.

\section{Exclusion criteria}

- $\quad$ Those who does not belong to adolescent age group.

\section{Statistical analysis}

Data entered using Microsoft Excel and analysed using SPSS 20.0. All conditions were reported using frequency and percentage.

\section{RESULTS}

There were a total of 720 adolescent girls sought cares for gynecological problems in the study, accounting for $16.8 \%$ of the total patients (4268) attending OPD of the tertiary care hospital. More than $80 \%$ (576) of the cases belonging to the age group of 15-19 years.

Table 1: Different types of problems in the adolescent population under study.

\begin{tabular}{|lll|}
\hline Condition & Number & Percentage \\
\hline Menstrual disorders & 362 & $49.8 \%$ \\
\hline Teenage pregnancy & 290 & $40.2 \%$ \\
\hline Vaginal discharge & 36 & $5 \%$ \\
\hline Mass per abdomen & 01 & $0.13 \%$ \\
\hline Trauma to genital tract & 02 & $0.27 \%$ \\
\hline Urinary tract infection & 29 & $4.02 \%$ \\
\hline
\end{tabular}

As shown in Table 1, out of 720 adolescent girls, menstrual disorders are seen in $362(49.8 \%)$ the commonest indication for the OPD consultation. Of these 362 cases puberty menorrhagia was seen in $11.32 \%$. Among $720.290(40.2 \%)$ of them were diagnosed as teenage pregnancy, among which 34 of them were unwanted pregnancy.

Other presentations include vaginal discharge 5\% (36), urinary tract infection $4.02 \%$ (29), mass per abdomen $0.13 \%$ (1) and trauma to genital tract $0.27 \%$ (2).

As shown in Table 2, out of 362 cases of menstrual disorders, irregular cycles are seen in 197 cases in that 187 cases polycystic ovarian syndrome is the cause of irregularity of cycles and 10 cases are due to hypothyroidism. 
Table 2: Menstrual disorders $(n=362)$.

\begin{tabular}{|c|ccc|}
\hline & $\begin{array}{l}\text { Menstrual } \\
\text { disorders }\end{array}$ & $\begin{array}{c}\text { No. of } \\
\text { Cases }\end{array}$ & Cases \\
\hline 1 & Amenorhea & 14 & \\
\hline a & $\begin{array}{l}\text { Primary } \\
\text { amenorhea }\end{array}$ & 3 & $\begin{array}{l}\text { Turners syndrome (2) } \\
\text { Imperforate hymen (1) }\end{array}$ \\
\hline b. & $\begin{array}{l}\text { Secondary } \\
\text { amenorhea }\end{array}$ & 11 & $\begin{array}{l}\text { Malnutrition (4) } \\
\text { Systemic illness (7) }\end{array}$ \\
\hline 2 & $\begin{array}{l}\text { Irregular cycles } \\
\text { PCOS (187) }\end{array}$ \\
\hline 3 & $\begin{array}{l}\text { Menorrhagia and } \\
\text { metrorhagia }\end{array}$ & 41 & \begin{tabular}{l} 
Thyroid disorders (10) \\
\hline
\end{tabular} \\
\hline
\end{tabular}

Table 3: Causes of menorrhagia.

\begin{tabular}{|ll|}
\hline Cause & Numbers \\
\hline Anovulatory bleeding & 31 \\
\hline Hypothyroid & 08 \\
\hline Idiopathic thrombocytopenic purpura & 02 \\
\hline
\end{tabular}

Out of 3 cases of primary amenorrhea, turners syndrome is the cause for primary amenorrhea and imperforate hymen in one case. Out of 11 cases of secondary amenorhea, malnutrition was seen in $4(36.6 \%)$ and systemic illness was found in 7 (63.6\%). Out of 89 cases, severe dysmenorrhea was seen in $11(12.3 \%)$.

As shown in the Table 3, Out of 41 cases of puberty menorrhagia, $9(21.9 \%)$ required hospital admission for management of severe anemia ( $\mathrm{Hb}$ less than $5 \mathrm{gm} \mathrm{\% )}$ resulting from puberty menorrhagia. Thyroid abnormality was found in $8(19.5 \%)$ of the cases and idiopathic thrombocytopenic purpura was seen in $2(4.8 \%)$.

\section{DISCUSSION}

Preeclampsia leads to increased perinatal morbidity and Adolescence is a transient and dynamic period between childhood and adulthood, presents with various gynecological problems.

The present study shows adolescent girls having gynecological problems attending outpatient department were $16.8 \%$ almost similar to study conducted by Chanda Karki et al $(12.39 \%) .^{5}$ Prakrithi et al have reported the incidence as $3.3 \% .^{7}$ Rajal et al have reported incidence of gynecological problems in adolescent girls as $2.3 \% .^{8}$ In our study incidence is more compared to study conducted by Rajal et al and Prakrithi et al.

The present study shows that menstrual disorders are the commonest gynecological problems (49.8\%) in adolescent girls and it is the commonest reason for opd consultation which ranges from amenorrhea to menorrhagia almost similar to study conducted by Chung et al $(47 \%)$ In the study conducted by Rajal et al, menstrual disorders were found in $34.6 \% .^{8}$ Prakrithi et al has reported incidence of menstrual irregularities as $60 \% .^{7}$

Amenorhea including primary and secondary was present in 14 girls. Turners syndrome was seen in 2 out of 3 primary amenorrhea cases and 1 was a case of imperforate hymen who underwent examination under anesthesia and treated with cruciate incision on hymen is now having regular menstruation. Most of the girls suffering from secondary amenorrhea 11 out of 14 cases were diagnosed have having systemic illness (7/11cases) or malnutrition (4/11), almost similar to study conducted by Kumari A et al. ${ }^{2}$

Teenage pregnancy is a common problem in developing countries like india and was seen in $40.2 \%$ of cases in our study. Chanda Karki reported incidence of Teenage pregnancies as $56.33 \% .^{5}$

Pregnancy in teenagers is a problem threatening the ultimate reproductive and child health. Out of $40.2 \%$ of cases one third were unwanted pregnancies. Most of the people among unwanted pregnancies who were from rural population were not aware of usage of contraception and complications of teenage pregnancy. Hence rural adolescent girls require strengthening of adolescent health programme in rural area in order to prevent criminal abortions.

In our study 197 adolescent girls came with history of irregular cycles out of which 187 were diagnosed as having polycystic ovarian syndrome based on clinical criteria of menstrual problems, features of hyperandrogenemia and ultrasonography features, associated problems like obesity was seen in half of them. Sebanti G et al in their study reported PCOS as the cause for secondary amenorrhea in $75 \%$ of cases. ${ }^{9}$

Out of 197 cases with irregular cycles, 10 cases were diagnosed as having hypothyroid features which were confirmed by doing thyroid profile.

In the present study puberty menorrhagia was seen in 41 cases and 9 out of 41 cases needed hospital admission in view of severe anemia ( $\mathrm{Hb}$ less than $5 \mathrm{gm} \%$ ) who required blood transfusion. Out of 41 cases 31 had anovulatory cycles and responded well to conservative management such as antifibrinolytics, oral contraceptive pills and oral progesterone. Two out of 41 cases were diagnosed as having idiopathic thrombocytopenic purpura managed with blood transfusion and oral progestogens. Menorrhagia due to hypothyroidism in our study was seen in 8 cases. Sheela $W G$ et al found hypothyroidism in 4 cases of menorrhagia. ${ }^{10}$

Study by Bhalerao-Gandhi A et al found hypothyroidism as the cause of menorrhagia in 2 cases. ${ }^{11}$ Kumari A study had hypothyroidism in 3 cases. $^{2}$ This finding is consistent with our study. 
In our study 89 adolescent girls came with dysmenorrhea out of which $12.3 \%$ of cases had severe dysmenorrhea. In the present study leucorrhea was seen in $5 \%$ of the cases. Leucorhea is frequent and embarrassing problem especially in low socioeconomic people. Remaining cases were of Mass per abdomen $(0.13 \%)$, trauma to geniatal tract $(0.27 \%)$, urinary tract infection was seen in $4.02 \%$ of cases.

\section{CONCLUSION}

The study shows around half of the adolescent girls are having menstrual disorders. One third were teenage pregnancies with most of them been 'wanted'. This alarming finding calls for strengthening of adolescent programme with targeted health education and behavioural change. Setting up separate adolescent clinics is necessary for efficient management of menstrual disorders in adolescents.

Funding: No funding sources Conflict of interest: None declared

Ethical approval: The study was approved by the Institutional Ethics Committee

\section{REFERENCES}

1. Creatsas G. Adolescent gynecology and obstetrics. Eur J Obstet Gynecol Reprod Bio. 1995;58(2):107-9.

2. Kumari A, Enclave A, Marg M, Colony BH. Adolescent gynaecological problems: a clinical study. J Evolut Med Dent Sci. 2013;2(9):1113.

3. Rathod AD, Chavan RP, Pajai SP, Bhagat V, Thoo P. Gynecological problems of adolescent girls attending outpatient department at tertiary care center with evaluation of cases of puberty menorrhagia requiring hospitalization. J Obstet Gynaecol India. 2016;66(Suppl 1):400-6.

4. Daftary SN, Patki A. Reproductive endocrinology and infertility, principles and clinical practice, New
Delhi. BI Publications, chapter 5, Puberty: Pediatric and Adolescent gynecology; 2009:44.

5. Karki C, Shrestha NS. Gynecological disorders of adolescent girls at Kathmandu Medical College Teaching Hospital. NJOG. 2008;3(2):44-7.

6. Agarwal AK, Agarwal A. A study of dysmenorhea during mestruation in adolescent girls. Indian $\mathbf{J}$ Community Med. 2010;35(1):159-60.

7. Goswami P, Ahirwar G. Adolescent gynecological problems:a prospective study. J Evolut Med Dental Sci. 2015;4(102):16709-12.

8. Thaker RV, Madiya AB, Chaudhari HD, Maru JD, Baranda SB. Health profile of adolescent girls visiting obstetrics and gynecology department of tertiary care hospital. Available at; http://dx.doi.org/10.18203/2320-1770.ijrcog2018 45 298.

9. Sebanti G, Dutta R, Sebani S. A profile of adolescent girls with gynaecological problems. J Obste Gynaecol Ind. 2005;55(4):353-5.

10. Sheela WG, Chellatamizh M, Mohanamba M, Vijayalakshmi P. Adolescent gynaecology problems in rural South India: a review of hospital admission in a tertiary care teaching hospital in Ammapettai, Tamil Nadu, India. Available at; http://dx.doi.org/10.18203/2320-1770.ijrcog20171 949.

11. Bhalerao-Gandhi A, Vaidiya R, Bandi F. Managing gynaecological problems in indian adolescent girls- a challenge of $21^{\text {st }}$ century. Obstet Gynecol Int J. 2015;3(1):70.

Cite this article as: Patil SS, Mahanthshetty $\mathrm{H}$, Supriya HM, Mahendra M. Gynecological problems of adolescent girls attending to rural tertiary care centre. Int J Reprod Contracept Obstet Gynecol 2019;8:2627-30. 